\title{
Analisis terjadinya hentakan dan suara keras pada suspensi belakang unit dump truck HD 785-7
}

\author{
Hendro Purwono ${ }^{1}$, Rasma ${ }^{2}$, Riki Effendi ${ }^{3}$ \\ Teknik Otomotif dan Alat Berat, Fakultas Teknik, Universitas Muhammadiyah Jakarta ${ }^{1,2}$ \\ Teknik Mesin, Fakultas Teknik, Universitas Muhammadiyah Jakarta ${ }^{3}$ \\ Jl. Cempaka Putih Tengah 27 Jakarta, 10510 \\ ${ }^{*}$ Corresponding author: hendro.purwono@ftumj.ac.id
}

\begin{abstract}
The suspension system on the machine unit is very important to support the unit weight against the road surface and also protect the transmission from the vertical vibration of the wheels to the body of the unit. When the unit passes a damaged or bumpy road at high speed, shock loads from the road surface will be felt, so the role of the suspension is crucial in protecting components from damage, maintaining operator comfort and undamaged loads. HD 785-7 unit is one type of dump truck that uses cylindrical pneumatic hydro suspension that contains nitrogen and oil gases to absorb loads or vibrations from the road surface. In its operation which functions as a material carrier in the mine area, there are often problems with the suspension especially at the rear because it is holding a heavier load. Therefore, research needs to be carried out aimed at finding the main causes and solutions to these problems using data collection methods, namely: field surveys, interviews, and library research. The results show that damage to the valve core causes the valve to leak and cause the chamber at the top of the cylinder suspension to be occupied by nitrogen gas to be reduced so that the suspension suffers harsh strokes when operated especially on damaged roads. Damage to the valve core is caused by the use of non-standard and too tight tools in its installation.
\end{abstract}

Keywords: hard suspension, valve core, feed valve, nitrogen gas, oil.

\begin{abstract}
Abstrak
Sistem suspensi pada unit alat berat sangatlah penting guna mendukung berat unit melawan permukaan jalan dan juga melindungi transmisi dari getaran vertikal roda ke badan unit. Ketika unit melewati jalan yang rusak atau bergelombang pada kecepatan tinggi maka akan terasa adanya beban kejut dari permukaan jalan sehingga peran suspensi sangat menentukan dalam melindungi komponen dari kerusakan, menjaga kenyamanan operator serta muatan tidak rusak. Unit HD 785-7 merupakan salah satu jenis dump truck yang menggunakan suspensi hidro pneumatik berbentuk silinder yang berisikan gas nitrogen dan oli untuk meredam beban atau getaran dari permukaan jalan. Dalam pengoperasiannya yang berfungsi sebagai pengangkut material di area tambang, sering terjadi masalah pada suspensi terutama pada bagian belakang karena menahan beban yang lebih berat. Oleh karena itu, perlu dilakukan penelitian yang bertujuan mencari penyebab utama dan solusi dari permasalahan tersebut dengan menggunakan metode pengumpulan data, yaitu: survei lapangan, wawancara dan library research. Hasilnya menunjukkan bahwa terjadinya kerusakan pada valve core yang menyebabkan feed valve mengalami kebocoran dan mengakibatkan ruangan pada bagian atas suspensi silinder yang ditempati oleh gas nitrogen menjadi berkurang sehingga suspensi mengalami hentakan-hentakan yang keras saat dioperasikan terutama di jalan yang rusak. Rusaknya valve core disebabkan oleh penggunaan perkakas yang tidak standar dan terlalu kencang di dalam pemasangannya.
\end{abstract}

Kata Kunci: suspensi keras, valve core, feed valve, gas nitrogen, oli. 


\section{Pendahuluan}

Sistem suspensi pada unit alat berat sangatlah penting guna mendukung berat unit melawan permukaan jalan dan juga melindungi transmisi dari getaran vertikal roda ke badan unit. Ketika unit melewati jalan yang rusak atau bergelombang pada kecepatan tinggi, maka akan terasa adanya beban kejut dari permukaan jalan sehingga peran suspensi sangat menentukan dalam melindungi komponen dari kerusakan, menjaga kenyamanan operator serta muatan tidak rusak.

Unit HD 785-7 merupakan salah satu jenis dump truck yang menggunakan suspensi hidro pneumatik berbentuk silinder yang berisikan gas nitrogen dan oli untuk meredam beban atau getaran dari permukaan jalan

Agar suspensi dapat berfungsi dengan baik maka perlu dilakukan perawatan unit secara berkala menggunakan Operation and Maintenance Manual (OMM) dan shop manual sebagai buku panduan. Oleh karena itu, pentingnya seorang mekanik memperhatikan proses perawatan dan penanganan serta pemeriksaan agar dapat meminimalisir kerusakan / gangguan pada suspensi.

Berdasarkan survei lapangan [3], sering terjadinya hentakan dan suara keras pada suspensi belakang disebabkan oleh beberapa faktor, yaitu:

1. Kekurangan dan kelebihan gas nitrogen pada suspensi.

2. Kebocoran pada feed valve

3. Kerusakan pada valve core.

Dari beberapa faktor penyebab tersebut dapat membuat kinerja suspensi tidak stabil dan mengalami masalah sehingga kenyamanan operator terganggu dan juga bisa merusak kompoen yang ada di sekitar susupensi seperti retak (crack) pada fasel. Untuk itu, perlunya dilakukan penelitian agar diketahui penyebab utamanya dan dilakukan langkah perbaikan agar unit dapat kembali dioperasikan serta langkah pencegahan sehingga masalah yang sama tidak terjadi kembali.

\section{Tinjauan Pustaka}

\section{Pengertian dump truck}

Dump truck merupakan salah satu alat berat yang banyak dipakai di pertambangan. Unit ini mempunyai fungsi untuk mengangkut material, batu bara, tanah, dan juga bisa buat meratakan tanah serta untuk memindahkan dan membuang material dengan kapasitas yang besar mulai 40 ton sampai 360 ton [1].

Dump truck merupakan produk Komatsu yang mempunyai ukuran yang beraneka ragam dan salah satunya adalah HD 785-7 seperti yang ditunjukkan pada gambar 1. Komatsu mengartikan bahwa :

HD : Heavy Duty

785 : Angka yang menunjukkan muatan dimana $785 \times 0,1=78,5$ ton

-7 : Angka yang menunjukkan bahwa unit telah mengalami modifikasi yang ke-7

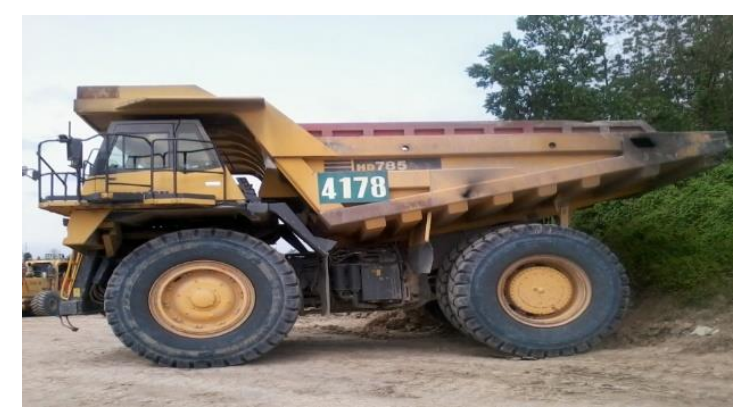

Gambar 1. Dump Truck HD 785-7 [3]

\section{Pengertian sistem suspensi}

Sistem suspensi adalah suatu sistem untuk mendukung berat unit melawan permukaan jalan dan melindungi transmisi dari getaran vertikal roda ke badan unit [1]. Ada suspensi yang memiliki pelengkapan untuk buffer. Ketika kendaraan melewati jalan yang rusak atau ada gundukan pada kecepatan tinggi pengendara dan penumpang merasakan ada beban kejut dari permukaan jalan, suspensi akan melindungi komponen dari kerusakan, menjaga kenyamanan supir dan penumpang serta muatan tidak rusak.

Komponen Utama Suspensi HD 785-7

Komponen utamanya seperti yang dapat ditunjukkan pada gambar 2 berikut ini. 


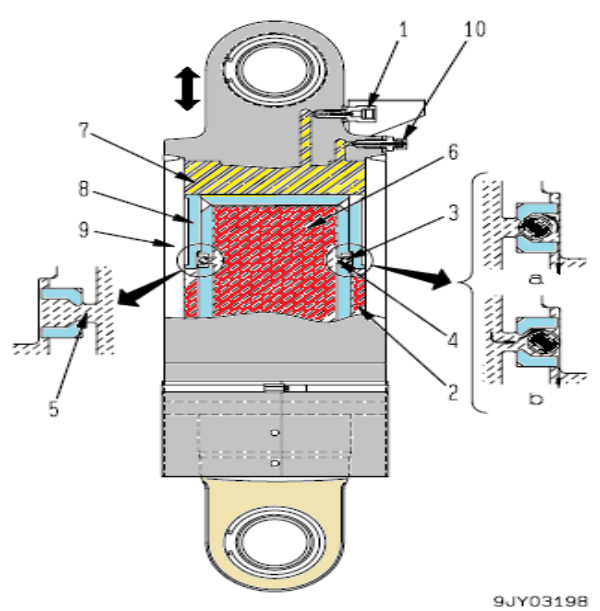

Gambar 2. Struktur dan Komponen

$$
\text { Sistem Suspensi [1] }
$$

Keterangan:

1. Feed valve

6. Oil chamber

2. Cavity

7. Nitrogen gas chamber

3. Check ball

8. Cylinder rod

4. Orifice

9. Cylinder

5. Orifice

10. Valve (for bleeding air)

\section{Cara Kerja Sistem Suspensi}

a. Saat Extending

Ketika unit melewati objek pada jalan yang rata, rod cylinder terdorong oleh roda pada axle dan tekanan nitrogen dalam chamber (7). sebagai hasilnya jumlah oli yang ada di cavity berkurang, dan tekanan di aplikasikan pada cavity. tekanan oli ini menutup orifice (4) dengan check ball, dan semuanya dikirim ke chamber melalui orifice (5). dalam keadaan ini, jumlah pengembalian oli ke chamber dibatasi untuk menyediakan sebuah efek menyerap guncangan.

b. Saat Retracting

Ketika unit sedang berjalan dan menabrak suatu objek di jalan, roda terdorong naik dan rod cylinder masuk ke dalam cylinder. ketika itu terjadi nitrogen di dalam chamber (7) terkompresi, oli di chamber (6) dikirim terus melalui kedua orifice (4) \& (5) ke cavity, dan cavity terus terisi lebih cepat dibanding extending.

\section{Metode Penelitian}

Untuk mengetahui penyebab utama terjadinya hentakan dan suara keras pada suspensi belakang unit dump truck HD 7857, maka peneliti melakukan metode pengumpulan data sebagai berikut:

1. Metode survei lapangan (field survey), yaitu pemeriksaan langsung pada obyek yang dituju untuk memperoleh data atau informasi yang diperlukan dalam menganalisa penyebab terjadinya hentakan dan suara keras pada suspensi belakang unit dump truck HD 785-7.

2. Metode wawancara (interview), yaitu mengumpulkan data melalui wawancara dengan customer ataupun operator serta melakukan diskusi di site (tempat timbulnya masalah itu terjadi)

3. Metode library research, yaitu mengumpulkan data-data dari membaca buku ataupun petunjuk cara kerja.

\section{Tahapan penyelesaian masalah}

Suspensi yang keras dapat menyebabkan kerusakan pada komponen lain dan ketidaknyamanan operator dalam mengoperasikan unit sebab dapat menimbulkan hentakan dan suara yang keras terutama jika membawa muatan dan melewati jalan yang tidak rata.

Adapun tahapan penyelesaian masalah yang dilakukan untuk mengetahui penyebab terjadinya hentakan dan suara keras pada suspensi belakang unit dump truck HD 785-7 ditunjukkan pada gambar 3.

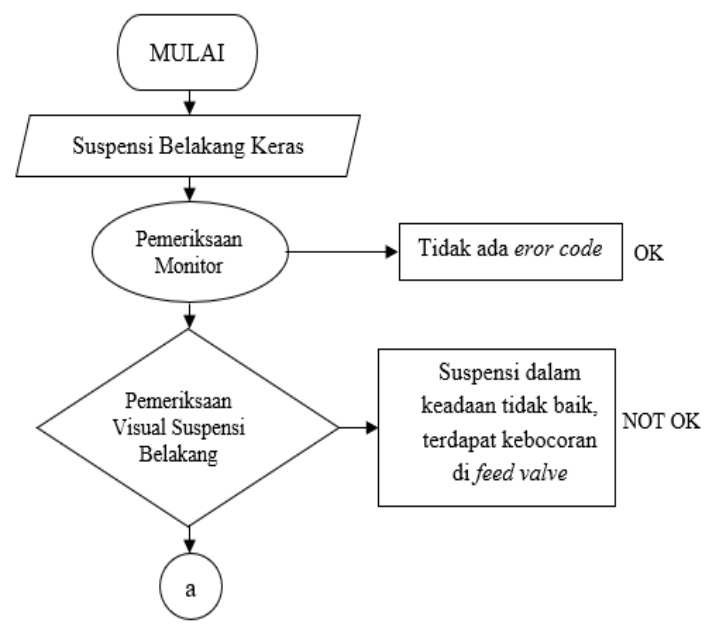




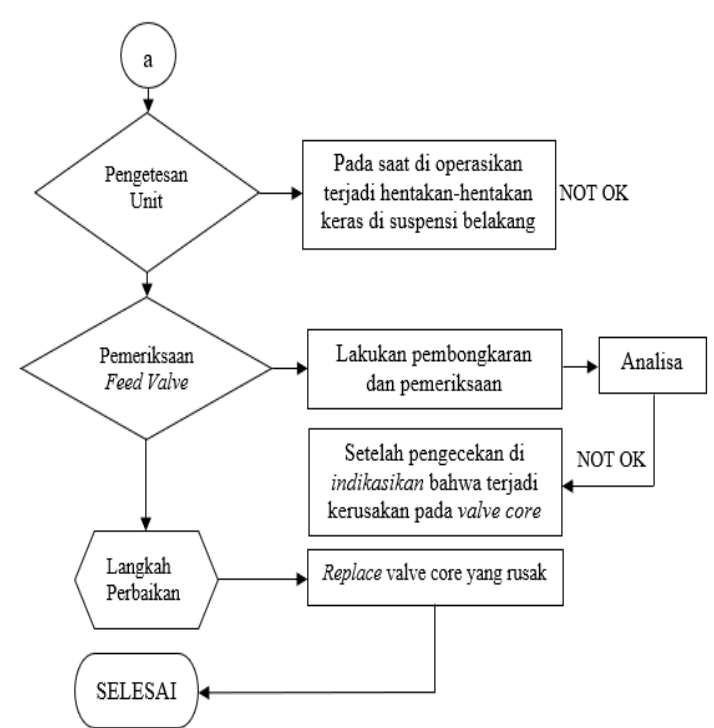

Gambar 3. Tahapan Penyelesaian Masalah

Penyelesaian masalah di mulai dengan melakukan pemeriksaan, pengukuran komponen dan pengetesan unit. Pemeriksaan terhadap penyebab terjadinya suspensi belakang keras (rear susupension hard) dilakukan dengan tujuan untuk mencari penyebab dari kerusakan yang terjadi dan kemudian melakukan perbaikan dengan cepat agar tidak menghambat proses produksi yang sedang berjalan, menghemat waktu breakdown unit dan mencegah terulangnya kembali kerusakan yang sama.

Oleh karena itu, proses pemeriksaan terhadap komponen-komponen harus dilakukan dengan teliti dan secermat mungkin agar segera dapat diketahui penyebab dari terjadinya kerusakan. Di saat pemeriksaan janganlah terburu-buru dalam membuka komponen karena sebagian komponen ada yang memilik sifat sensitif yang tinggi ( apabila komponen yang lain dibuka dengan tidak hati-hati, maka dikhawatirkan akan merusak komponen yang lain).

Pemeriksaan ini dimulai dengan menunjukkan penyebab yang paling mungkin dapat dilokasikan dari gejala kerusakan (simple inspection) tanpa menggunakan alat. Penyebab kemungkinan terjadinya hentakan dan suara keras pada suspensi belakang unit HD 785-7 adalah kekurangan atau kelebihan nitrogen sehingga perlu dilakukan pemeriksaan, diantaranya:

\section{Ground test unit}

Tujuannya adalah untuk mengetahui kondisi unit tersebut dalam keadaan bermasalah atau tidak [1].

2. Pemeriksaan secara visual

Pemeriksaan dilakukan pada sistem suspensi dengan tujuan untuk mengetahui kondisinya dalam keadaan bocor atau tidak [1].

a) Pemeriksaan Feed Valve

Tujuannya adalah untuk memastikan kondisi feed valve dalam kondisi rusak/bocor atau tidak seperti terlihat pada gambar 4 berikut ini.

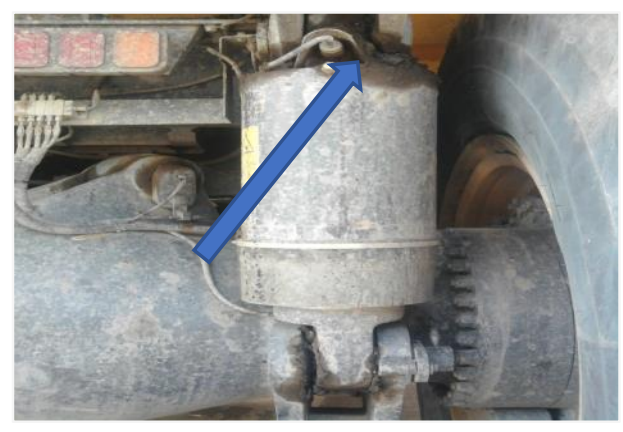

Gambar 4. Pemeriksaan Feed Valve

Adapun cara pemeriksaannya adalah sebagai berikut:

1. Memarkir unit di tempat yang rata dan aman

2. Memasang wheel chock pada ban

3. Menyiapkan alat bantu

4. Memeriksa feed valve dengan teliti

b) Pemeriksaan Valve Core

Tujuannya adalah untuk memastikan valve core dalam keadaan rusak atau tidak seperti terlihat pada gambar 5 berikut ini.

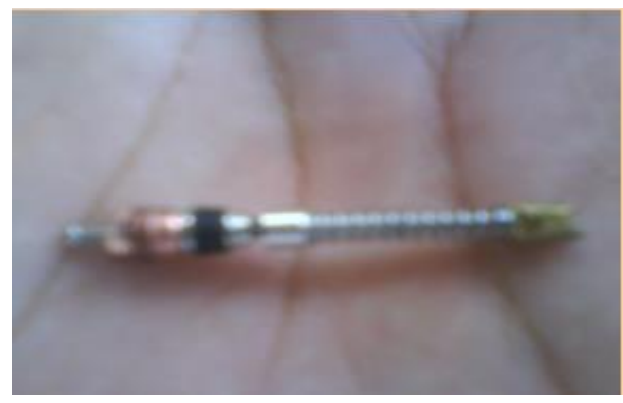

Gambar 5. Pemeriksaan Valve Core 


\section{Pengukuran rod cylinder}

Tujuannya adalah untuk mengetahui panjang rod cylinder masih dalam keadaan standar atau tidak seperti terlihat pada gambar 6 berikut ini [1].

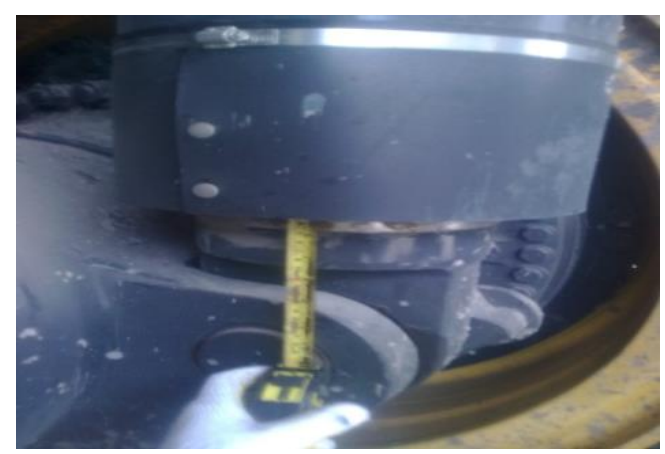

Gambar 6. Pengukuran Rod Cylinder

\section{Hasil dan Pembahasan}

Setelah diperoleh data-data dari hasil pengetesan unit, pemeriksaan dan pengukuran maka diperoleh hasil sebagai berikut:

1. Hasil dari ground test menunjukkan bahwa pada saat unit HD 785-7 dioperasikan timbul hentakan dan suara keras di suspensi belakang.

2. Terdapat kebocoran di feed valve sehingga mengakibatkan nitrogen yang berada di dalam chamber akan keluar.

3. Terdapat kerusakan pada valve core. Hal ini disebabkan oleh:

a. Saat pemasangan valve core terlalu kencang

b. Kurang maintenance yang baik

4. Hasil pengukuran menunjukkan bahwa panjang rod cylinder sebesar $150 \mathrm{~mm}$ dimana standarnya adalah $199 \pm 10 \mathrm{~mm}$ sehingga dapat dikatakan tidak sesuai standar. Hal ini juga yang dapat menyebabkan terjadinya hentakanhentakan keras di suspensi belakang saat unit dioperasikan.

Setelah didapatkan data hasil pengetesan unit, pemeriksaan dan pengukuran maka langkah selanjutnya adalah melakukan perbaikan atau penggantian komponen-komponen yang sudah rusak atau tidak standar lagi dan pencegahan agar masalah yang sama tidak terulang kembali.

\section{Langkah perbaikan}

Langkah perbaikan yang dilakukan mengikuti prosedur shop manual dan Operation Maintenance Manual [4].

1. Melakukan flushing pada komponen suspensi (feed valve dan valve core) dan sistem suspensi secara keseluruhan dengan benar dan bersih dengan mengikuti prosedur sebagai berikut:

a. Bleeding oil yang kotor

b. Menyiapkan drum tampungan untuk flushing

c. Melakukan flushing suspension (feed valve dan valve core) dengan menggunakan solar sampai bersih

d. Setelah bersih, mengelap dengan majun

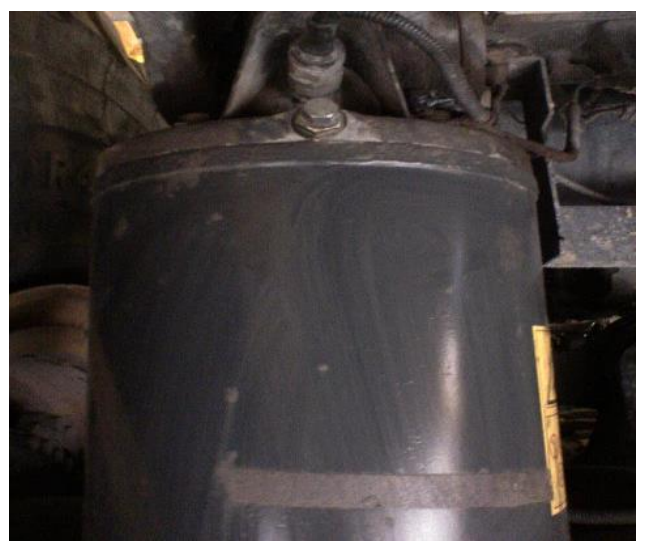

Gambar 7. Flushing Suspension

2. Penggantian valve core dengan part number yang sesuai standar seperti terlihat pada gambar 8 berikut ini [2].

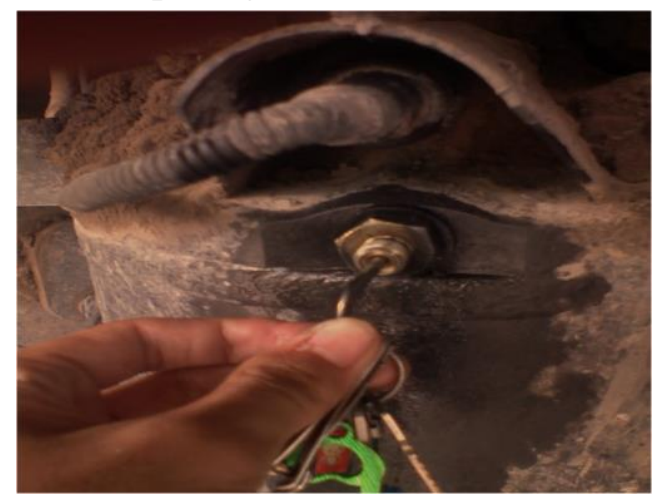

Gambar 8. Penggantian Valve Core

3. Adjusting Level Oil and Charging Langkah-langkahnya adalah sebagai berikut:

a. Menghubungkan pressurized oil pump (B1) dengan suspensi pada 
nipple nomor 3. Kendorkan plug nomor 1 lalu pompakan oli SAE 10 ke suspensi hingga gelembung udara yang keluar dari nipple no 1 tidak ada lagi

b. Melepaskan (disconnect) oil pump lalu pasang valve dan kencangkan, begitu juga dengan sensor suspensinya

c. Memeriksa pelindung rod untuk memastikan sudah terpasang cukup kencang.

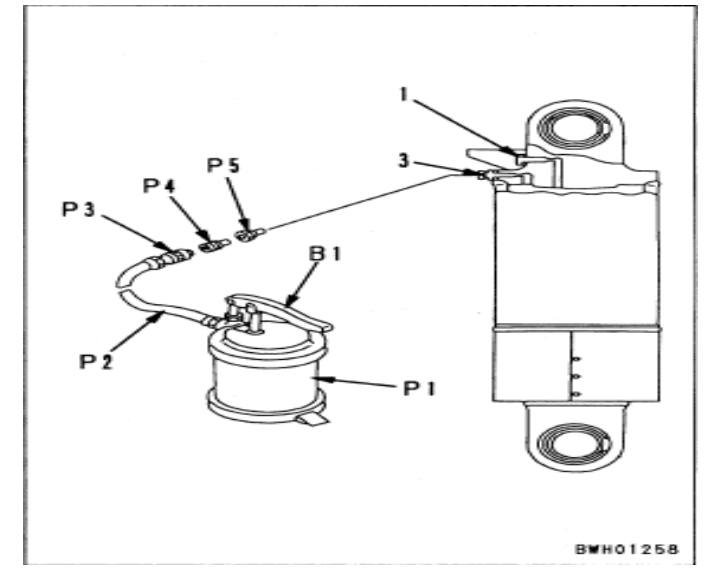

Gambar 9. Charging Oil Rear Suspension

4. Pengisian Nitrogen

Adapun proses pengisian nitrogen adalah sebagai berikut:

a. Memasang charging tools suspensi seperti yang ditunjukkan gambar 9 dan menghubugkan ke nipple 5 pada suspensi kiri dan kanan

b. Membersihkan hose sebelum dipasang ke valve dengan gas nitrogen bertekanan $10 \mathrm{~kg} / \mathrm{cm}^{2}$ untuk membersihkan kotoran yang ada di dalam hose.

c. Dalam pemasangan (connection) hose tidak perlu kencang sekali tetapi cukup jika sudah tidak bocor

d. Memutar valve H10a hingga membuka core valve suspensi agar gas bisa masuk ke suspensi

e. Membuka valve (2) hingga terbaca tekanannya pada gauge $\mathrm{H} 12$

f. Memutar ke kanan regulator $\mathrm{H} 11 \mathrm{a}$ hingga gauge H13 menunjukkan minimal $10 \mathrm{~kg} / \mathrm{cm}^{2}$ di atas tekanan setting suspensi $\left(28 \mathrm{~kg} / \mathrm{cm}^{2}\right)$ g. Membuka valve H7 (kiri dan kanan) secara bersamaan sehingga kedua suspensi naik. Jika belum naik juga maka regulator $\mathrm{H} 11 \mathrm{a}$ dinaikkan hingga suspensi naik. Setelah ketinggian rod tercapai ("a" : $220 \pm$ $10 \mathrm{~mm}$ ), tutup valve $\mathrm{H} 7$. Kemudian mengendorkan valve H11a untuk menutup dari tabung (1)

h. Membuka valve $\mathrm{H} 7$ untuk melihat tekanan masing-masing suspensi secara bergantian. Jika tekanan melebihi standar, maka buka drain plug pada valve $\mathrm{H} 7$ secara bergantian.
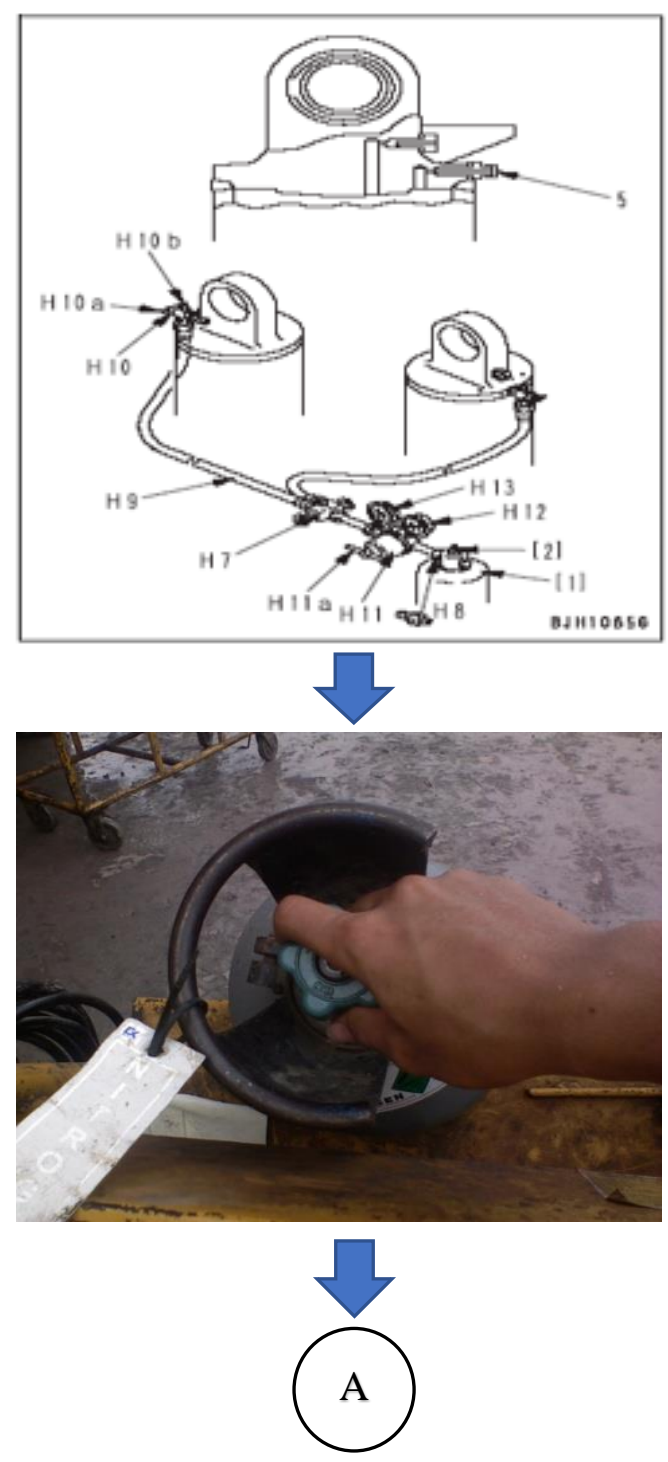


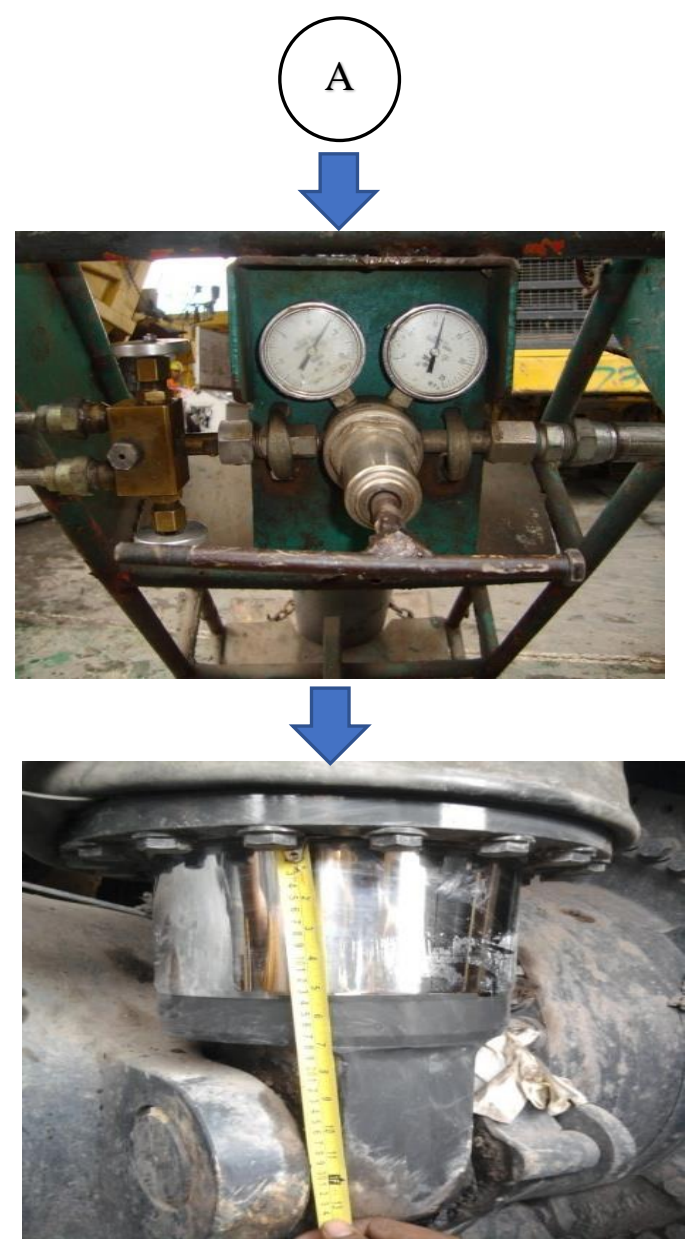

Gambar 10. Proses Pengisian Nitrogen

5. Ground Test Unit

Hal yang dilakukan adalah pengukuran panjang rod dengan menggunakan tolls convex scale dan pengetesan unit di jalan. Hasilnya dapat ditunjukkan pada tabel 1 berikut ini.

Tabel 1. Hasil Ground Test Unit HD 785-7

PENGUKURAN AKTUAL STANDAR KETERANGAN

\begin{tabular}{cccc}
\hline $\begin{array}{c}\text { Panjang Rod } \\
\text { Cylinder }\end{array}$ & $187 \mathrm{~mm}$ & $199 \pm 10 \mathrm{~mm}$ & Normal \\
\hline Pengetesan Unit & $\begin{array}{l}\text { Tidak Ada } \\
\text { Hentakan }\end{array}$ & $\begin{array}{l}\text { Tidak Ada } \\
\text { Hentakan }\end{array}$ & Normal \\
\hline
\end{tabular}

\section{Langkah Pencegahan}

Ada hal-hal yang perlu dilakukan agar tidak timbul masalah yang sama, yaitu:

1. Pada saat melakukan adjusting nitrogen, jangan terlalu kencang saat memasang valve core sebab dapat merusak valve core

2. Gunakan alat bantu (tool) yang standar
3. Lakukan adjusting yang baik dan benar, selalu melakukan perawatan unit secara berkala menggunakan Operation and Maintenance Manual (OMM) dan Shop Manual sebagai buku panduan dan petunjuk untuk perawatan unit yang lebih baik.

\section{Kesimpulan}

Berdasarkan hasil pengamatan, pemeriksaan, pengukuran dan analisa maka dapat disimpulkan bahwa masalah yang timbul disebabkan karena terdapat kerusakan pada valve core suspensi belakang yang disebabkan oleh pemasangannya yang terlalu kencang dan maintenance nya kurang baik. Rusaknya valve core dapat menyebabkan terjadinya kebocoran feed valve sehingga mengakibatkan nitrogen yang berada di dalam chamber akan keluar. Keluarnya nitrogen dapat mengakibatkan panjang rod cylinder tidak lagi standar sehingga pada saat dioperasikan timbul hentakan dan suara keras pada suspensi belakang unit dump truck HD 785-7.

\section{Referensi}

[1] Shop Manual HD 785-7. 2006. PT United Tractors Tbk,

[2] Part Book. 2011. PT United Tractors Tbk.

[3] Inspection Langsung Dari Lapangan Hima Panca Utama. 2016.

[4] OMM HD 785-7. 2005. PT United Tractors Tbk. 